\title{
A STUDY OF NONLINEAR PUSH OVER ANALYSIS OF PRECAST STRUCTURE
}

\author{
Asha Uday Rao ${ }^{1}$, Aiyappa T.B ${ }^{2}$, H.L Suresh ${ }^{3}$ \\ ${ }^{1}$ Associate Professor (Senior Scale), Department of Civil, Manipal Institute of Technology, Karnataka, India \\ ${ }^{2}$ Post Graduate Student, Structural Engineering, Manipal Institute of Technology, Karnataka, India \\ ${ }^{3}$ Director, Structural Engineer, Civil Tech India Pvt Ltd, Bangalore, Karnataka, India
}

\begin{abstract}
The vital contrast between the cast in site R.C. frame structures and the prefabricated structure is that the prefabricated structures are consists of different members cast in production facilities away from the construction site. The static and dynamic behavior of the structure mainly depends upon elements and connections. The behavior of prefabricated structures depends on the performance of the various connections between the precast members. The research reported in this paper concerns the nonlinear push over analysis of the precast 5 storey frames with fixed and nonlinear moment resisting beam column connections. The Structural frames were made of typical columns where considerable rotations and shear forces influenced at the connections. The step displacement was induced in the frame and where progressive increment to the point where considerable damage was obtained, either at beam column connection or at the base of column. The results are compared with different connections with identical sectional property ordinary moment resisting frame structure. It was proved that pinned connections can accommodate large rotations, more than $0.10 \mathrm{rad}$, without significant loss of their strength. However, if they are damaged, large joint rotations and the repetition of the ground shaking might increase the damage. Also, it was found that the vertical component of earthquake does not seem to be important.
\end{abstract}

Keywords: Precast, Nonlinear Moment Resistance Connections, Push Over, Seismic Design, Seismic Response, ETABS

\section{INTRODUCTION}

Precast concrete construction is not a new construction technique it's as old as traditional construction itself. But it was not extensively used and its application was only limited to industrial structures and long span elements like bridge girder, tunnel lining, retaining wall etc. Precast concrete construction was not used in large scale in commercial and residential projects due to many problems The major drawbacks were,

- Lack of standard guidelines by building authorities,

- Complicated analysis design procedures which was not possible without advancement of computer application in analysis and design.

But in present days precast concrete construction used in phase of industrialization of construction Industry. This technique is gaining importance in present days supported by Advancement in automations on production of precast elements. Introduction of heavy lifting equipment and transportation vehicle. Improvement in concrete technology, also required strength and mechanical properties can be achieved easily in concrete now a day.

Advancement in connection technique to assemble precast component like post stressing, dowel connection, steel anchor connections etc. The cons of these technique are
Improved quality control can be maintained in industrial production. Better indoor working condition to cast precast components. The shortage of onsite skilled workers is solved by precast construction.

The precast components are cast in precise steel moulds hence onsite formwork is not required. Cost effective production due to cost reduction from formwork, scaffolding. Time saving is achieved hence it is erected easily without huge time gap for curing, formwork, reinforcement fabrication on site. Slender members like Tsection and I-section can be produced to meet the architectural demand and material saving. Transportation cost is reduced when the project site is in economical reach. But the major difficulty faced by structural engineers in implementing this technique in large scale project because its seismic performance was not satisfactory which majorly depend on connection type used to connect one member with other and lack of stiffening elements for horizontal stiffness of structure with shear wall and core walls.

\section{MODELING AND ANALYSIS OF STRUCTURE}

To evaluate the Precast structures with Nonlinear connection using pushover method three different structures was prepared. The structural details are given below. 
The FEM based analysis software ETABS is utilized to produce for nonlinear connection links in the precast system 3D model and analyze. ETABS is capable to stimulate the member non-linear performance of space frames under dynamic or static loadings, considering both nonlinearity of section geometry and inelasticity of material. ETABS approach of static forces or displacements as well as dynamic effect by acceleration and is capable to perform eigenvalues, non-linear static pushover and non-linear dynamic analyses. Four structures have been taken in the study is mentioned below.

1. Ordinary Moment Resistant Frame (OMRF) Building of $\mathrm{G}+4$ with RC Beam Column system, typical floor height of $3.5 \mathrm{~m}$

2.Precast RC Beam Column system with fixed link of G+4, typical floor height of $3.5 \mathrm{~m}$.

3.Precast RC Beam Column system with non-linear Ordinary Moment Resistant Frame (OMRF) link (Hybrid Connection) of $\mathrm{G}+4$, typical floor height of $3.5 \mathrm{~m}$.

Live load on the floor is taken as $2 \mathrm{kN} / \mathrm{m}^{2}$ and on the roof is $1.5 \mathrm{kN} / \mathrm{m}^{2}$. Floor finish on the floor and weathering course on the roof is taken as $1 \mathrm{kN} / \mathrm{m}^{2}$ respectively for the both the building. The seismic weight is calculated according to IS 1893-2002. The Unit weight of concrete is $25 \mathrm{kN} / \mathrm{m} 3$ modulus of elasticity $\mathrm{E}=2.5 \times 107 \mathrm{kN} / \mathrm{m} 2$ and shear modulus of concrete $\mathrm{G}=1.06 \times 107 \mathrm{kN} / \mathrm{m} 2$ is taken. Beams and column element are defined as 'frame elements' with the suitable identical dimensions and reinforcement respectively. The interaction between soil and structure are not considered and the base of columns are restrained in all six degrees of freedom.

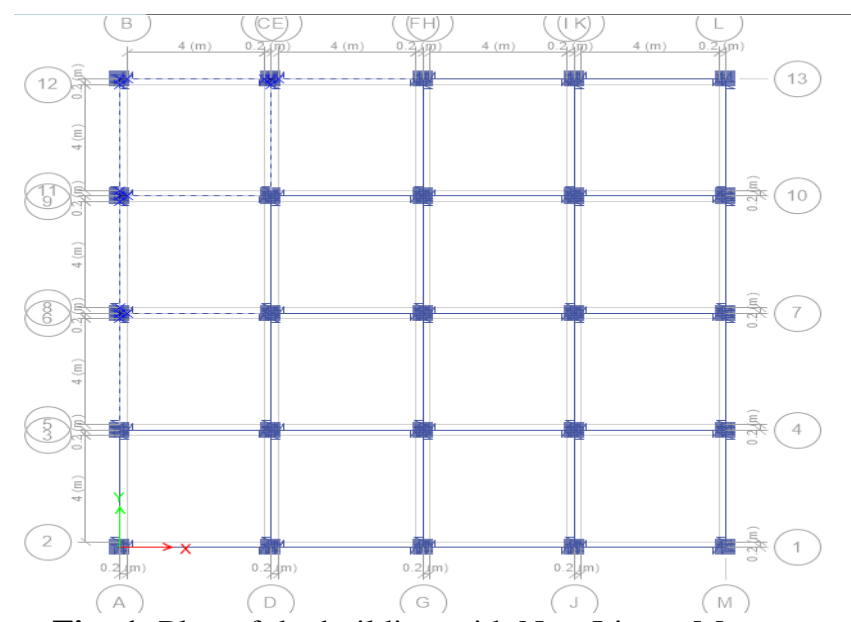

Fig -1: Plan of the building with Non-Linear Moment resistant

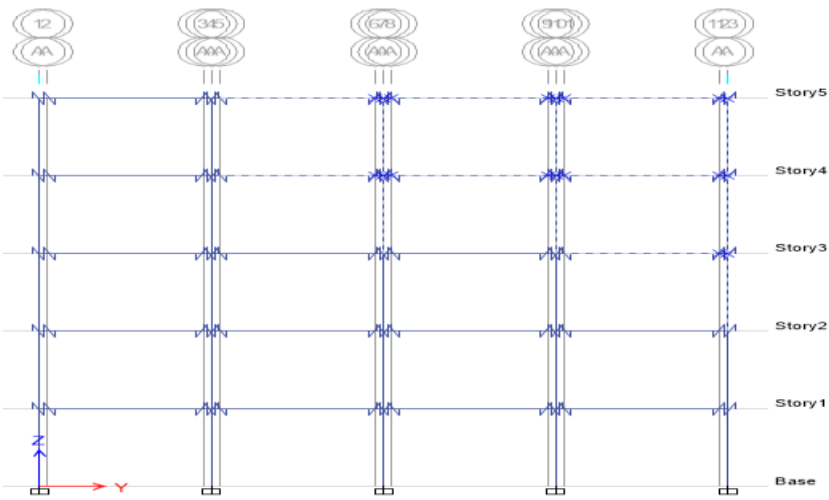

Fig -2: Elevation of the building with Non-Linear Moment resistant

\subsection{Connection Details}

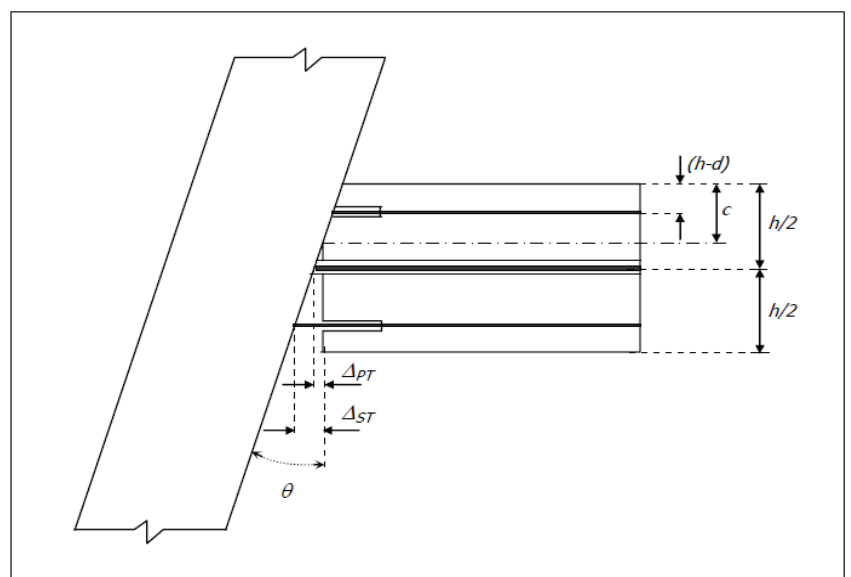

Fig -3: The beam column hybrid connection. (Pampanin)

\subsection{Pushover Analysis Method}

The static non-linear method for calculating the strength capacity of the structural system in the range of postelasticity. Pushover analysis include inducing a calculated pattern of lateral load which is applied along the height of building. At displacement control node at different levels of the building lateral forces are evenly applied proportionally until structural elements reached to collapsed state and respective deformation are obtained. At every load increment corresponding lateral displacement is obtained for particular base shear. For design earthquake on the structure, the displacement is obtained by capacity curve. The structural failure at member level at target displacement will represent damage of the structure when design earthquake is applied.

\section{RESULTS AND DISCUSSION}

Comparison curve of story displacement versus height curves for ordinary moment resistant frame, fixed beam column connection and beam column connection with moment resistant nonlinear hinge. 


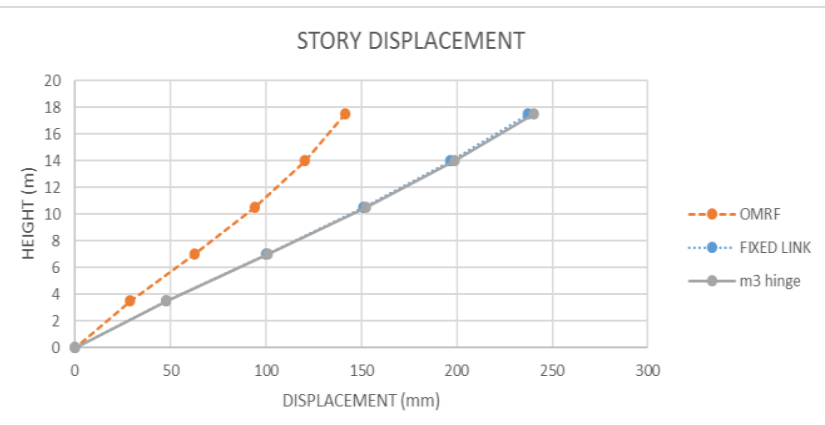

Fig 4: Story displacement vs height Comparison curve

Comparison of story drift versus height for ordinary moment resistant frame, fixed beam column connection and beam column connection with moment resistant nonlinear hinge shows large variations

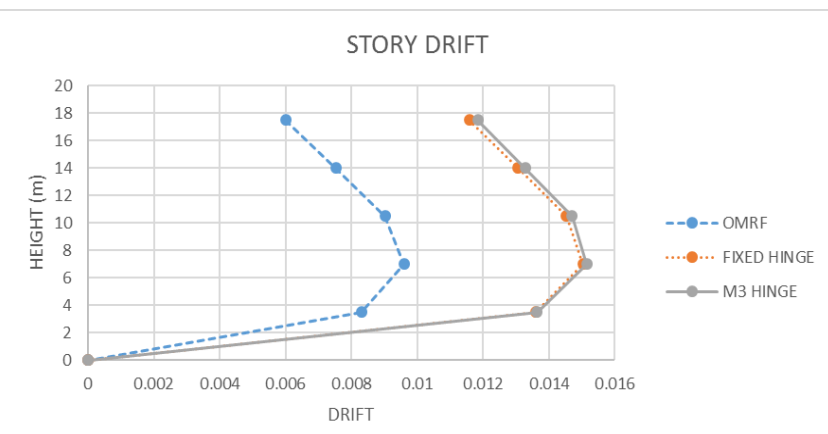

Fig -5: Comparison curve of story drift vs height curve

\subsection{Pushover Curve}

ETABS is used to obtain the nonlinear response of a five storied structure by push over analysis. Pushover analysis the analyses are carried out for various nonlinear condition and the following parameters are compared namely; capacity spectrums, displacement pushover curve.

Pushover curve or capacity curve is a graph of base shear(V) vs. roof displacement(D). The base shear applied in the structure with respect to performance point is obtained by this curve

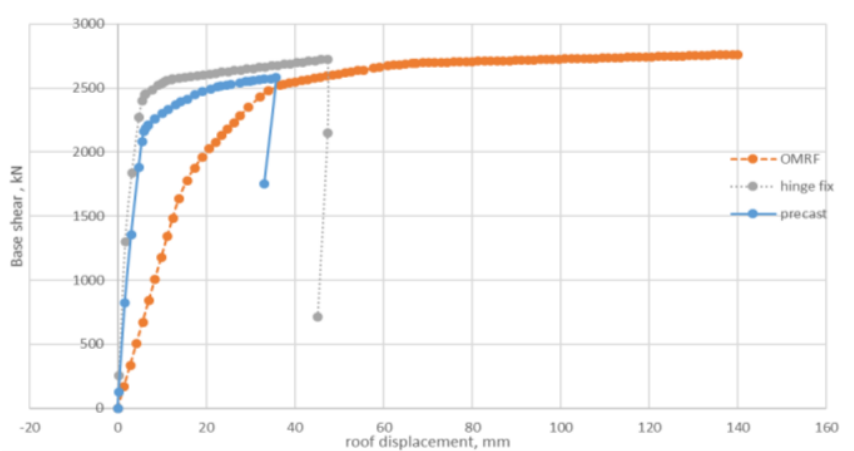

Fig -6: Uniform lateral load pattern Curve for Pushover

\subsection{Capacity Spectrum}

Capacity spectrum is the capacity curve obtained from coordinate of base shear(V) vs. roof displacement(D) into coordinates of spectral acceleration(Sa) vs. spectral
displacement(Sd ). By overlapping demand spectrum with capacity curve converted into spectral coordinates the performance point is obtained. For particular spectrum acceleration with respect to performance point all structure has to be designed.

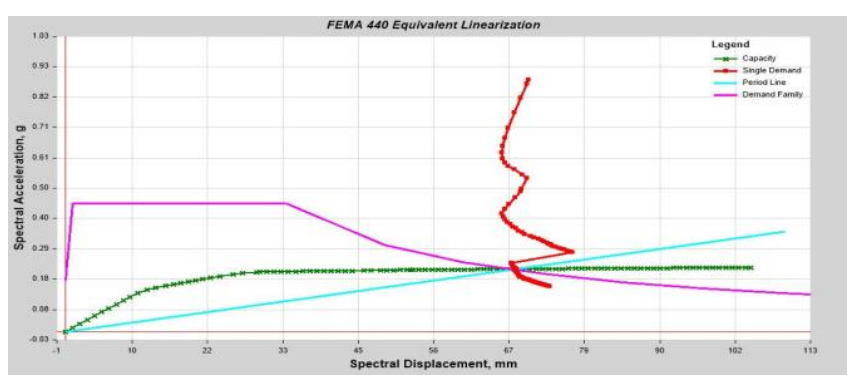

Fig -7: Capacity spectrum of five storey building for OMRF.

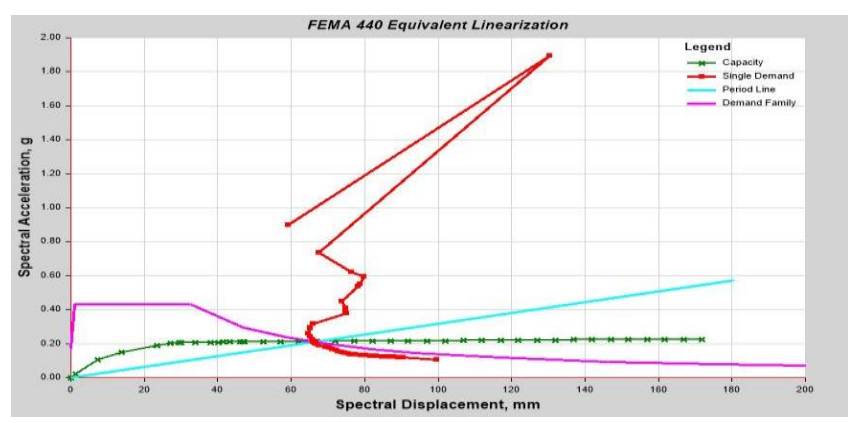

Fig -8: Capacity spectrum of Five storey Structure for fixed beam column connection.

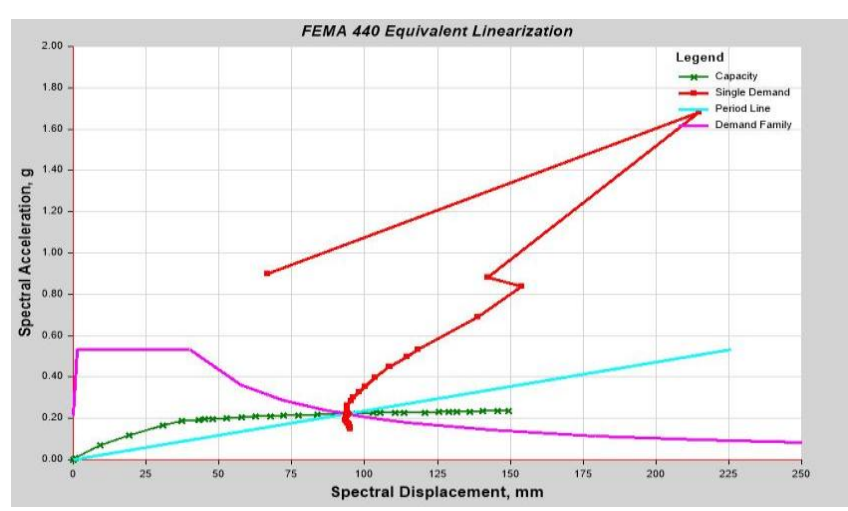

Fig -9: Capacity spectrum of five storey building for beam column connection with moment resistant nonlinear hinge.

Table I. For Base Shear(V), Displacement(D), Spectral Acceleration(Sa) and Spectral Displacement(Sd) at Performance point.

\begin{tabular}{|c|c|c|c|c|c|}
\hline $\begin{array}{c}\mathrm{SL} \\
\mathrm{NO}\end{array}$ & CASE & $\mathrm{V}$ in $\mathrm{kN}$ & $\begin{array}{c}\mathrm{D} \text { in } \\
\mathrm{mm}\end{array}$ & $\begin{array}{c}\mathrm{Sa} \\
(\mathrm{g})\end{array}$ & $\begin{array}{c}\mathrm{Sd} \text { in } \\
\mathrm{mm}\end{array}$ \\
\hline 1 & OMRF & 2715 & 89.5 & 0.219 & 68.3 \\
\hline 2 & $\begin{array}{c}\text { FIXED } \\
\text { CONNECTION }\end{array}$ & 2596 & 17.6 & 0.214 & 66.3 \\
\hline 3 & $\begin{array}{c}\text { NON LINEAR } \\
\text { CONNECTION }\end{array}$ & 2482.76 & 20 & 0.222 & 93.9 \\
\hline
\end{tabular}




\section{CONCLUSIONS}

Supported by the above results plotted from these analyses, the below conclusions are made for the study of precast Structures over ordinary moment resistant frame structure.

- Pushover curves plotted for three different structure indicate spectral displacement(Sd) of OMRF is maximum compare to other two precast structures at respective performance point.

- The obtained displacements in performance point from capacity spectrum for three structural types, its observed that the OMRF show more deflection for the base shear but in both the type of precast structure similar brittle behavior is observed.

- In the story displacement and story drift graph its observed that the precast system undergoes large displacement along the height compared to OMRF structural system. Therefore, precast system need to be provided with lateral stability element like shear wall or bracing system to increase the seismic performance.

\section{ACKNOWLEDGEMENT}

I would like to thanks to my father Mr. BOPAIAH T.P, my mother M/s DECHAMMA P.A, my dear sister, professors, and friends to their continuous support in many ways for the completion of this project.

\section{REFERENCES}

[1] Sivakkolundu Vernu, "Section, Member and System Level Analyses for Precast Concrete Hybrid Frames." Iowa State University,Sri Sritharan Iowa State University, sri@iastate.edu

[2] Ari Wibowoa, John L. Wilson a, Nelson T.K. Lamb and Emad F. Gada,b "Collapse modelling analysis of a precast soft storey building in Australia" A Faculty of Engineering and Industrial Sciences, Swinburne University of Technology, Australia.

[3] Matej Fischinger and Miha Kramar and Tatjana Isakovi'c "Cyclic response of slender RC columns typical of precast industrial buildings" Received: 11 September 2007 / Accepted: 26 February 2008 / Published online: 15 March 2008.

[4] R.B. Fleischman, Tucson and Arizona "Development of a seismic design methodology for precast concrete floor diaphragms" USA C.J. Naito Department of Civil and Environmental Engineering, USA.2008.

[5] A.Belleri, M. Torquati and P. Riva "Displacement Based Assessment for precast concrete structures: application to a three story plane frame" Department of Design and Technology, University of Bergamo, Italy 2012.

[6] Georgia D. Kremmyda and Yasin M. Fahjan and Spyros G. Tsoukantas "Nonlinear FE analysis of precast $R C$ pinned beam-to-column connections under monotonic

[7] Blaž Zoubek and Matej Fischinger and Tatjana Isakovic. "Estimation of the cyclic capacity of beam-to-column dowel connections in precast industrial buildings".

[8] Kai Sum Cheung San Jose "Nonlinear Pushover Analysis of a One-Story Precast Concrete Cladding System" State University (2010).
[9] IS 456:2000 "Indian Standard Plain and Reinforced Concrete Code of Practice".

[10] FEMA-273 [1997] "NEHRP Guidelines for the seismic rehabilitation of buildings, Report No. FEMA273," Federal Emergency Management Agency, October. [11] IS 1893 (Part 1):2002 Indian Standard "Criteria for Earthquake Resistant Design of Structures" Part 1 General Provision and Buildings, (Fifth Revision).

[12] ETABS Nonlinear Version 11 Software Package, Nonlinear Manuals.

\section{BIOGRAPHIES}

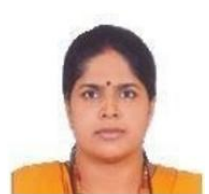

Asha Uday Rao : Associate Professor (Senior Scale) Department of Civil Engineering. Manipal Institute of Technology, Karnataka, India. (Industrial Structure), Ph.D B.E. (Civil), M.Tech.

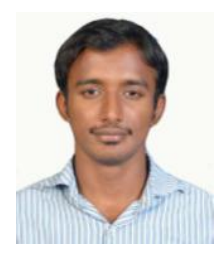

\begin{abstract}
Aiyappa T.B : PG student, Civil Engineering, Manipal institute of technology, Manipal.
\end{abstract}

